\title{
The Effects of Elasticity Of Demand For Product Quality And Discount Rate In Dual-Channel Supply Chains
}

\author{
Farida Pulansari*, Sinta Dewi, Isna Nugraha and Salaf Syah Maulana \\ Industrial Engineering, Faculty of Engineering, Universitas of Pembangunan Nasional "Veteran” Jawa Timur, Indonesia
}

\begin{abstract}
This research employed a development model investigating offline and online demand functions in the dual-channel supply chain (DCSC) structure by Widodo He explains that the DCSC structure has a problem determining each channel's prices and proposes a mathematical model approach between offline channels and online channels. The critical parameter is the relative ratio of customer acceptance on the online and the offline channels. Besides using the relative ratio of customer acceptance on the online and the offline channels, this research employed an additional variable, namely the elasticity of demand for quality and discount rate. Adding a new variable to the DCSC structure increases profit systems. This study aimed to investigate the best prices for offline and online channels to get optimal profits. Therefore, optimal prices were discovered for consumers and companies with the two sales structures running simultaneously. The model development profits showe that profits in both offline and online channels increased. In the current condition, the offline channels tended to dominate. However, the analysis of this study showed that online sales could control the sales structures. The overall profits of IDR 2,532,106.00 were obtained by setting a price of IDR87,296.00 on offline channels and Rp. 89,300.00 on the online channel.
\end{abstract}

Keyword : Supply Chain, Elasticity of Demand, Quality Product

\section{Introduction}

Prices play a crucial role in the macroeconomy, consumers, and companies. Dai et al. [1] report that pricing strategies have important and popular topics in dual-channel supply chains. In the economy, the price of a product affects the level of wages, rents, interests, profits, and production factors, such as labor, capital, and entrepreneurship. The price can be one of the factors that consumers consider before buying a product. Besides, it is one of the marketing mixes that bring income for companies. Research by Wang et al. [2] summarizes that pricing fixing is determined by the agents' attitude involved in the pricing.

The emergence of the internet has helped humans in all aspects of life and has full-shares in people's lives. A survey by Puskakom UI (Center for Communication Studies, Universitas Indonesia) and APJII (Association of Indonesian Internet Service Providers) has reported that the number of internet users reached 132.7 million out of 256.2 million Indonesian population in 2016. This number shows that the internet users increased by $51.8 \%$ in 2016 from 88 million users in 2014.

The application of e-commerce technology in business is one of the pivotal factors supporting the success of a company's product. To accelerate and increase sales, the company conducts direct- conventional transactions at stores (an offline channel) and benefits from the rapid development of information technology by selling its products on the website (online channel). Online channels in a business can increase the supply chain flexibility in the demand fulfillment process [3]. Batarfia [4] reports that companies utilize ecommerce as their marketing tools to remain competitive and increase the accessibility of their products.

The simultaneous use of offline channels and online channels is known as dual-channel supply chain (DCSC). The company's desire to successfully sell products faster and increase competitiveness is the reason for expanding its business to a broader market. The implementation of DCSC can increase the consumer surplus and social welfare [5]. Inventory management is pivotal in the DCSC. Research by Fengqin et al. [6] concludes that DCSC can reduce operating costs and improve the efficiency of supply chains. Furthermore, DCSC can assist a business to observe market information and reach more customers. [7]. In addition, the use of dual-channels can give consumers a choice to use another channel when there a stock-out occurs on the other channel. This condition is beneficial for business people who implement DCSC

\footnotetext{
* Corresponding author: farida.ti@upnjatim.ac.id
} 
because it can increase the flexibility of the company's supply chains [8].

Companies that meet consumer demands through several sales channels in the supply chain are complementary to meet consumer demands [9]. In the DCSC concept, the price of a product is different in each channel and based on consumers' channel preferences influenced by their added value [10]. The aspect that influences consumer preferences is transaction costs compulsorily paid by consumers before purchasing products [11].

Kana $\mathrm{R}$ is one of the well-known product brands of Muslim hijab fashion owned by a well-known Muslim fashion company. This company has offline and online product distribution channels in its business processes and still manages its channels intuitively without any data analysis on most of its decision-making process.

DCSC principles aim to increase profits of the whole system by evaluating prices and pricing strategies for both channels. Therefore, implementing DCSC can be a solution and a way to increase online demands and overall profits. This study aimed to evaluate the product pricing systems and develop optimal pricing scenarios to obtain better profits.

\section{Research Methods}

This research employed the DCSC model by Widodo [12]. From the initial model, the parameters of elasticity of demands for quality and discount rates were added. The developed model was also equipped with objective and limiting functions. The data collection and parameter data processing were conducted for for the model's initial input values After verifying and validating the model, this research optimized the model to determine optimal profit solutions. The results were then used to analyze the sensitivity to determine changes in profits from critical parameters that affect the changes.

Furthermore, this chapter will explain the research model and numerical experiments to determine the optimal results of the conducted research.

\subsection{Identification and Definition of Operational Variables}

The dependent variable of this study was the price of products on online and offline channels to generate optimal profits. Meanwhile, the independent variables were the maximum demand on offline channels, the level of consumer preference, the ratio of the elasticity of of demands to price, the ratio of the demand elasticity to quality, the discount rate, and the unit cost.

\subsection{Modeling}

In this study developed a nonlinear programming model to obtain prices on offline and online channels that generate optimal profits. The model of offline channel demands developed by Widodo [12] is as follows.

$$
\mathrm{Ds}=d_{s}^{\max }-\frac{\beta(P s-P o)}{(1-\rho)}
$$

Widodo, et al. 5..... also developed a model of online channel demands.

$D o=\frac{\boldsymbol{\beta}((\boldsymbol{P s}(\boldsymbol{\rho}+\mathbf{a}))-\boldsymbol{P o})}{\boldsymbol{\rho}(\mathbf{1}-\boldsymbol{\rho})}$

The demand models employ the phenomenon in which consumers prefer buying products online than offline. Meanwhile, the model of this study will receive additional parameters, namely the elasticity ratio of demands to quality and discount rates.

The development model of the offline channel demands is as follows.

$D s=d_{s}^{\max }-\beta \frac{((1+\mathrm{a}) P s-P o}{(1-\rho)}+\alpha \frac{(\theta \times P s)}{P s}$

Meanwhile, the model of the online channel demand is as follows.

$D o=\frac{\beta((P s(\rho+\mathrm{a}))-P o)}{\rho(1-\rho)}+\alpha \frac{(\theta \times P o)}{P o}$

The offline channel profitability function is as follows.

$G s=d_{s}^{\max }-\beta \frac{((1+\mathrm{a})) P s-P o)}{\rho(1-\rho)}(P s-\mathrm{Pd})$

The online channel profitability function is as follows.

$G o=\frac{\beta((P s(\rho+a))-P o)}{\rho(1-\rho)}(P o-P d)$

The total profitability function is as follows.

$\mathrm{Gtot}=(\mathrm{Gs}+\mathrm{Go}+\mathrm{Gd})$

Model Notation:

Ps = Product prices on offline channels

Po = Product prices on online channels

$\mathrm{Pd}=$ Product prices on distributor

Ds $\quad=$ Offline channel demand

Do $\quad=$ Online channel demand

$d_{s}^{\max }=$ Maximum demand on offline channel

a $\quad=$ Price change factor

$\rho \quad=$ Consumer preference

$\beta \quad=$ Elasticity of demands to price

$\alpha \quad=$ Elasticity of demand to quality

$\Theta \quad=$ Discount rate

$\mathrm{Gd}=$ Distributor profitability function

Based on the objective function compiled, the systems received limiting functions to resemble the actual conditions. The limiting function of the model is as follows.

1. $P_{d}, P_{s}, P_{o} \geq \mathrm{Cu}$ shows that the selling price of distributors, online channel, and offline channel must be greater than the production costs (cost units).

2. $P_{S} \geq \frac{P_{o}}{\rho}$ indicates that when the selling prices on the offline channels are greater than thoseI on the online channels, the demands for the online channel occur. 
3. $P_{s}, P_{o} \geq P_{d}$ indicates that the products' selling price on the offline and online channels must be greater than or equal to the distributor prices.

4. $P_{S} \leq \frac{d_{S}^{\max }(1-\rho)+\beta P_{o}}{\beta(1+\alpha)}$ shows that the demands for offline products (Ds) are positive.

5. $d_{o}^{l t} D_{s} \leq D_{o}$ shows the lowest limit on the online channel demands. The $d_{o}^{l t}$ shows that the lowest limit on the online demand channel is determined from the proportion of demands on the offline channels as the minimum value $D_{o}$

6. $D_{o} \leq d_{o}^{u t} D_{s}$ shows the highest limit on the online channel demands. The $d_{o}^{u t}$ is determined from the proportion of requests in the offline channel as the maximum value $D_{o}$

7. $0<\rho<1$ indicates that the limit value of $\rho$ must be between 0 to 1 .

\section{Numerical Experiment}

The numerical experiment was conducted to test the model made using the parameter data obtained from the observed objects. The initial stage was validation to determine whether the model compiled was valid.

\subsection{Validation}

The model was validated by inputting the existing data on the demand or profit function that has been prepared previously. The validation was conducted on several parameters affecting the company's demands or profits. Moreover, the validation was conducted by doing several experiments and changing the related parameters. The results of validating the price of the offline channel on offline demands are presented in Table 1.

Table 1. The Data Input for Offline Price Validation on Offline Demands

\begin{tabular}{|c|c|c|c|c|c|}
\hline Iteration & Ps & Po & $\boldsymbol{d}_{\boldsymbol{s}}^{\max }$ & $\boldsymbol{\rho}$ & $\mathbf{A}$ \\
\hline \multirow{3}{*}{8} & $\mathbf{7 6 , 0 0 0}$ & 79,200 & 75 & 0.96 & 0.83 \\
\cline { 2 - 6 } & $\boldsymbol{\Theta}$ & $\mathbf{C u}$ & $\mathbf{a}$ & \multicolumn{2}{|c|}{ Ds } \\
\cline { 2 - 6 } & $20 \%$ & 61,000 & 0 & \multicolumn{2}{|c|}{99} \\
\hline
\end{tabular}

The validation process was conducted by changing the Ps values while the other parameter values were left constant. The validation results show that the higher the Ps value or the specified offline channel's price is, the lower the expected demand will be. This condition is valid if the graph shows the same result.

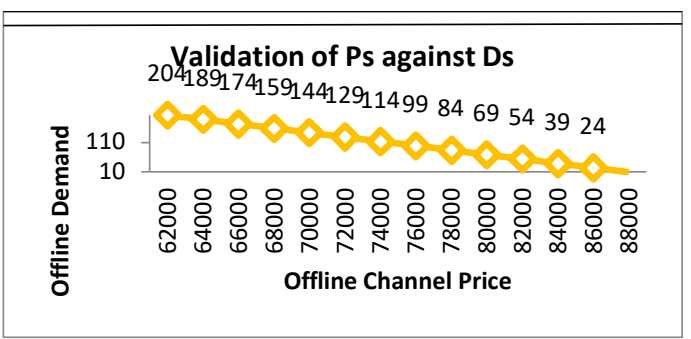

Fig.1. Validation Graph, Ps Against Ds
Figure 1 indicates that the offline demand function compiled is valid. Therefore, the applied model is correct as the graph shows a decline; when the price set on the offline channel was more incredible, the demand for the offline channel decreases.

\subsection{Verification}

Verification is conducted using MATLAB software by carrying out the profit optimization process to discover prices in each channel. In the program's initial step, the code for the profitability of the objective function was written, and thus, the verification results were found. The verification process was conducted by checking if there were some errors in the m-file used. The process began with making the initial coding containing the essential components and input parameters, as shown in Figure 2.

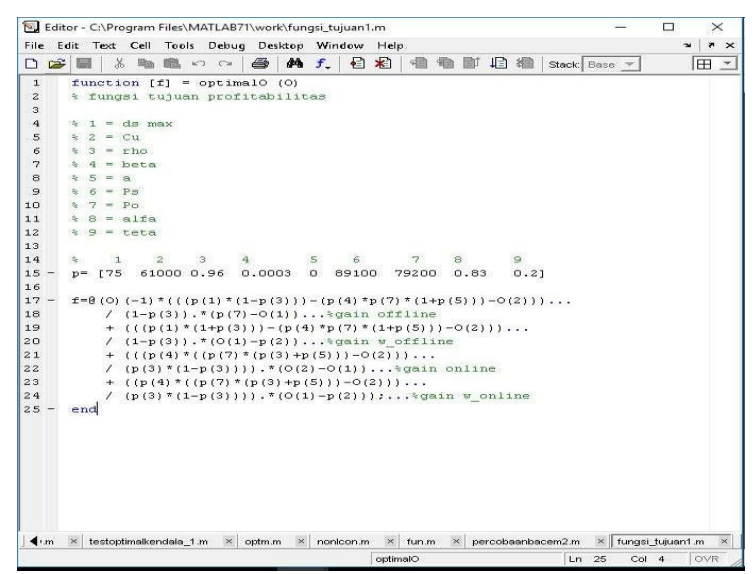

Fig.2. Profitability of Objective Functions

The primary function (syntax) used in this optimization was find minimum of constrained nonlinear multivariable function (FMINCON). The basic syntax used for the running function is as follows.

(x, fval, exitflag) $=$ fmincon (..)

With $x$ containing the problem used: $\mathrm{x}=$ fmincon (fun, $\mathrm{x} 0, \mathrm{~A}, \mathrm{~b}$, Aeq, beq)

With

fun $\quad=$ The name of the file containing the optimized function

$\mathrm{x} 0 \quad=$ Initial starting point

A $\quad=\mathrm{A}$ linear inequality constraint $\mathrm{Ax} \leq \mathrm{b}$; given as () if not applied

$\mathrm{b}=\mathrm{A}$ linear inequality constraint $\mathrm{Ax} \leq \mathrm{b}$; given as ( ) if not applied

Aeq $=$ Linear equation constraint Aeq $\mathrm{x}=$ beq ; given as ( ) if not applied

beq $=$ Linear equation constraint Aeq $\mathrm{x}=\mathrm{beq}$; given as ( ) if not applied

Then, the function was verified by running on the three $\mathrm{m}$-file functions created and pressing F5 or calling the $\mathrm{m}$-file function. In addition, the verification was conducted by checking the exit flag value in the command window on MATLAB.

The initial solutions were obtained by inputting the limiting functions that would be used in the model one by one. When the exit flag value showed a value of 1 , 
the optimal solution with the limiting function was obtained; it was also possible to add other limiting functions. If the exit flag value showed a value other than 1 , it was necessary to relax the limiting function causing no optimal solution to discover. The obtained results are presented in Table 2.

Table 2. Price Optimization Numerical Experiment Results

\begin{tabular}{|l|r|r|r|r|r|r|r|r|r|r|r|}
\hline \multicolumn{1}{|c|}{$\begin{array}{l}\text { The } \\
\text { Limiting } \\
\begin{array}{l}\text { Function } \\
\text { Fulfilled }\end{array}\end{array}$} & Trial & Cons & Beta & $\begin{array}{c}\text { Exit } \\
\text { flag }\end{array}$ & Ps & Po & Ds & Do & Gs & Exit flag & Ps \\
\hline No & 1 & $1-9$ & 0.01 & 4 & 332,288 & 302,477 & 149 & 24 & $13,952,062$ & $30,733,450$ & $44,685,512$ \\
\hline No & 2 & $1-9$ & 0.002 & 4 & 17,668 & 169,247 & 84 & 20 & $-9,805,488$ & $7,633,600$ & $-2,171,888$ \\
\hline No & 3 & $1-9$ & 0.001 & 4 & 15,128 & 124,827 & 72 & 20 & $-5,890,464$ & $3,306,480$ & $-2,583,984$ \\
\hline No & 4 & $1-9$ & 0.0005 & 4 & 102,608 & 102,627 & 64 & 64 & $1,594,752$ & $2,136,320$ & $3,731,072$ \\
\hline No & 5 & $1-9$ & 0.0004 & 4 & 87,296 & 89,300 & 56 & 64 & $1,194,536$ & 595,800 & $1,790,336$ \\
\hline Yes & 6 & $1-9$ & 0.0003 & 1 & 86,573 & 89,346 & 41 & 63 & 543,414 & $1,281,176$ & $1,824,590$ \\
\hline Yes & 7 & $1-9$ & 0.0002 & 1 & 87,296 & 89,300 & 45 & 63 & 660,510 & $1,254,744$ & $1,915,254$ \\
\hline Yes & 8 & $1-9$ & 0.0001 & 1 & 87,296 & 89,300 & 51 & 62 & 748,578 & $1,312,834$ & $2,061,412$ \\
\hline Yes & 9 & $1-9$ & 0.00009 & 1 & 87,296 & 89,300 & 54 & 56 & $1,159,920$ & 529,760 & $1,689,680$ \\
\hline Yes & 10 & $1-9$ & 0.00008 & 1 & 86,573 & 89,346 & 59 & 55 & $1,196,697$ & 603,060 & $1,799,757$ \\
\hline Yes & 11 & $1-9$ & 0.00007 & 1 & 86,573 & 89,346 & 67 & 53 & $1,358,961$ & 634,800 & $1,993,761$ \\
\hline Yes & 12 & $1-9$ & 0.00006 & 1 & 86,573 & 89,346 & 72 & 48 & 954,288 & $1,478,280$ & $2,432,568$ \\
\hline Yes & 13 & $1-9$ & 0.00005 & 1 & 87,296 & 89,300 & 77 & 43 & $1,116,346$ & $1,415,760$ & $2,532,106$ \\
\hline Yes & 14 & $1-9$ & 0.00004 & 1 & 366,318 & 332,087 & 81 & 38 & $8,593,128$ & $23,708,370$ & $32,301,498$ \\
\hline Yes & 15 & $1-9$ & 0.00003 & 1 & 638,538 & 568,957 & 95 & 24 & $21,328,260$ & $42,010,570$ & $63,338,830$ \\
\hline Yes & 16 & $1-9$ & 0.00002 & 1 & 791,658 & 702,197 & 94 & 24 & $28,604,952$ & $50,309,300$ & $78,914,252$ \\
\hline
\end{tabular}

Table 3. Price optimization results

\begin{tabular}{|c|c|c|c|c|}
\hline \multirow[b]{2}{*}{ Constrain } & \multirow{2}{*}{$\begin{array}{c}\text { Beta } \\
\text { Parameter }\end{array}$} & \multicolumn{3}{|c|}{ MATLAB Output } \\
\hline & & $\begin{array}{l}\text { Exit } \\
\text { Flag }\end{array}$ & Ps & Po \\
\hline $1-9$ & 0.00005 & 1 & 87,296 & 89,300 \\
\hline & & & & \\
\hline & & & & \\
\hline
\end{tabular}

Table 3 signifies that the active limiting function is the limiting functions 1 to 9 with the prices on the offline channel (Ps) of IDR87,296.00. Meanwhile, and the price on the online channel is IDR89,300.00. This price shows the number of demands along with the profits on each channel.

Table 4. Number of Demands and Profits

\begin{tabular}{|l|l|l|l|l|}
\hline \multicolumn{5}{|c|}{ Manual Output } \\
\hline Ds & Do & Gs & Go & Gtotal \\
\hline 77 & 43 & $1,116,346$ & $1,415,760$ & $2,532,106$ \\
\hline
\end{tabular}

Table 4 shows that the number of demands on the offline channel (Ds) is 77 units while the number of demands on the online channel (Do) is 43 units. The profit on offline channel is IDR1,116,346.00. Meanwhile, the profit on the online channel is IDR1,415,760.00. Thus, the total profit obtained is IDR2,532,106.00. There was a significant increase in the number of requests on on existing conditions. The same phenomenon also occurred in the total profit obtained from the research results. The comparison between the existing conditions and the research results is presented in the following sub-chapter.

\subsection{Price Comparison Results}

Table 5 shows the comparison of total profits in the existing conditions and research results. In the existing price, the profit was obtained using the general formula of the selling price minus the cost of production. Meanwhile, the profit prices of the experimental results were obtained from the dual-channel supply chain formula.

Table 5. Price Comparison Results

\begin{tabular}{|l|l|l|}
\hline \multicolumn{1}{|c|}{ Parameter } & \multicolumn{1}{|c|}{$\begin{array}{c}\text { Existing Price (in } \\
\text { IDR) }\end{array}$} & \multicolumn{1}{|c|}{$\begin{array}{c}\text { Experiment } \\
\text { Result (in IDR) }\end{array}$} \\
\hline Offline price (Ps) & $89,100.00$ & $87,296.00$ \\
\hline Online Price (Po) & $79,200.00$ & $89,300.00$ \\
\hline $\begin{array}{l}\text { Demand offline } \\
\text { (Ds) }\end{array}$ & 75 & 77 \\
\hline $\begin{array}{l}\text { Demand online } \\
\text { (Do) }\end{array}$ & 10 & 43 \\
\hline Profit offline (Gs) & $1,807,500.00$ & $1,116,346.00$ \\
\hline Profit online (Go) & $142,000.00$ & $1,415,760.00$ \\
\hline Gtotal & $1,949,500.00$ & $2,532,106.00$ \\
\hline
\end{tabular}

Table 5 presents the differences between the existing prices and the results of the numerical experiments. The total profit on the experimental results is IDR2,532,106.00, while the profit on the existing price is IDR1,949,500.00. These findings show that the experimental results are more significant than the existing prices. The difference between the existing profit and the results of the numerical experiment is IDR582,606.00. The profit obtained in the experimental results is greater than that in the existing conditions because the offline channels still control the product sales in the existing conditions. Sales outlets still tended to sell products offline. However, the 
condition was different when other parameters affecting sales existed; these parameters were buyers' preference or tendency to purchase products on online channels, the elasticity of demands to quality, and discount rates. The online channel can finally shift the offline sales trends. This phenomenon was evidenced by the increasing profits obtained on the online channels; the existing conditions earned IDR142,000.00 while the results of numerical experiments earned IDR1,415,760.00. These results enable the online channel to dominate all product sales strategies because consumers' preference to buy online is getting bigger. The sensitivity analysis revealed the changeable values depending on the influencing parameters, as presented in Table 6 .

\subsection{Sensitivity Analysis}

Sensitivity analysis was conducted to discover which parameters critically influencing the system's total profits and change the analyzed parameters. In contrast, the other parameters remained unchanged to explore the effects of emerging changes on the total profits. The analysis was conducted by giving treatment as well as increasing and decreasing $10 \%$ of the price of the experimental parameters linearly - the parameters of sensitivity of $d_{s}^{\max }$ are presented in Table 6.

Table 6. Parameters of Sensitivity Analysis of $d_{s}^{\max }$

\begin{tabular}{|c|c|c|c|}
\hline Treatment & $\begin{array}{c}\text { Ds } \\
\max \end{array}$ & $\begin{array}{c}\text { Existing (in } \\
\text { IDR) }\end{array}$ & $\begin{array}{c}\text { Result (in } \\
\text { IDR) }\end{array}$ \\
\hline$-40 \%$ & 45 & 67,666 & 282,106 \\
\hline$-30 \%$ & 52.5 & 538,062 & 844,606 \\
\hline$-20 \%$ & 60 & $1,008,458$ & $1,407,106$ \\
\hline$-10 \%$ & 67.5 & $1,478,854$ & $1,969,606$ \\
\hline $0 \%$ & 75 & $1,949,500$ & $2,532,106$ \\
\hline $10 \%$ & 82.5 & $2,419,896$ & $3,094,606$ \\
\hline $20 \%$ & 90 & $2,890,292$ & $3,657,106$ \\
\hline $30 \%$ & 97.5 & $3,360,688$ & $4,219,606$ \\
\hline $40 \%$ & 105 & $3,831,084$ & $4,782,106$ \\
\hline
\end{tabular}

\section{Results and Discussion}

This study has revealed that the applied model is valid. The verification using the MATLAB software and numerical experiments was conducted to determine prices on offline channels and online channels. The price on the offline channel was IDR84,698.00, and the price on the online channel was IDR75,973.00. The experimental results earned a profit on the offline channel for IDR1,116,346.00, while the profit on the online channel was IDR1,415,760.00.

The price set by the management could not achieve the optimum profits because sales outlets still relied on offline sales without increasing their online sales strategies. On the contrary, if the management had improved the sales strategy on the online channel, it would have received significantly profitable results. The analysis results showed that the initial price conditions set by the management earned a profit of IDR142,000.00 on the online channel. Meanwhile, the experimental results earned profit of IDR 1,415,760.00 on the online channel.

This study employed the numerical experiment model by Erwin Widodo (2011) to determine prices for offline and online channels. The main factor in selecting the model was consumers' preference for buying products on online channels rather than offline. Meanwhile, in developing the research model, two new parameters, namely the elasticity of demands to quality and discount rates, were added. The parameter of elasticity of demands to the quality obtained a value of 0.86 . A discount rate of $10 \%$ was given for online channels and $20 \%$ for offline channels. Meanwhile, the numerical experiments obtained that the optimal price on the offline channel (Ps) for IDR87,296.00 with 77 units of offline demand (Ds). The optimal price on the online channel (Po) was IDR89,300.00 with 43 units of online demands (Do). Meanwhile, the offline channel (Gs) profitability earned IDR1,116,346.00 while the online channel (Go) earned IDR1,415,760.00. The total profit of the existing conditions was IDR $1,949,500.00$, and the total profit of the experimental results was IDR2,532,106.00.

\section{References}

[1] L. Dai, X. Wang, X. Liu, and L. Wei, "Pricing strategies in dual-channel supply chain with a fair caring retailer," Complexity, vol. 2019, 2019.

[2] R. Wang, Z. Chang, and S. Yan, "The pricing strategy of dual-channel supply chain with riskaverse agents and heterogeneous preference consumers," Kybernetes, 2021.

[3] Y.-C. Tsao and P.-Y. Su, "A dual-channel supply chain model under price and warranty competition," Int. J. Innov. Comput. Inf. Control, vol. 8, no. 3, pp. 2125-2135, 2012.

[4] R. Batarfi, M. Y. Jaber, and S. Zanoni, "Dualchannel supply chain: A strategy to maximize profit," Appl. Math. Model., vol. 40, no. 21-22, pp. 9454-9473, 2016.

[5] C. Wang, D. Yang, and Z. Wang, "Comparison of dual-channel supply chain structures: ECommerce platform as different roles," Math. Probl. Eng., vol. 2016, 2016.

[6] X. Fengqin, "Inventory Strategy of DualChannel Supply Chain from Manufacturer\&apos;s Perspective," Int. J. Manag. Fuzzy Syst., vol. 4, no. 2, p. 29, 2018, doi: 10.11648/j.ijmfs.20180402.14.

[7] N. M. Modak and P. Kelle, "Managing a dualchannel supply chain under price and deliverytime dependent stochastic demand," Eur. J. Oper. Res., vol. 272, no. 1, pp. 147-161, 2019.

[8] W. K. Chiang and G. E. Monahan, "Managing inventories in a two-echelon dual-channel supply chain," Eur. J. Oper. Res., vol. 162, no. 2, pp. 325-341, 2005.

[9] E. Widodo, K. Takahashi, K. Morikawa, I. N. Pujawan, and B. Santosa, "Managing sales return in dual sales channel: its product 
substitution and return channel analysis," Int. J. Ind. Syst. Eng., vol. 9, no. 2, pp. 121-149, 2011.

[10] J.-M. Chen and C.-I. Chang, "Dynamic pricing for new and remanufactured products in a closed-loop supply chain," Int. J. Prod. Econ., vol. 146, no. 1, pp. 153-160, 2013.

[11] T.-P. Liang and J.-S. Huang, "An empirical study on consumer acceptance of products in electronic markets: a transaction cost model," Decis. Support Syst., vol. 24, no. 1, pp. 29-43, 1998.

[12] E. Widodo, "Penetapan Harga Berbasis Penerimaan Konsumen di Dual-Channel Supply Chain," J. Tek. Ind., vol. 15, no. 1, pp. 1-8, 2014. 